\title{
Catalytically enhanced absorption of sulphur species from odorous air streams: A new technology for odour abatement
}

\author{
Fred E. Hancock ${ }^{\mathrm{a}, *}$, Frank King ${ }^{\mathrm{a}}$, Wendy R. Flavell ${ }^{\mathrm{b}}$, M.Saiful. Islam ${ }^{\mathrm{c}}$ \\ a ICI Katalco, PO Box 1, Billingham, Cleveland, UK \\ ${ }^{\mathrm{b}}$ Department of Physics, UMIST, Manchester, UK \\ ${ }^{\mathrm{c}}$ Department of Chemistry, University of Surrey, Guildford, Surrey, UK
}

\begin{abstract}
Nuisance odours, often containing sulphur species, are a high profile emission from many types of plants in the process industries. In particular in the food processing industries and sewage treatment sulphur compound emissions are common. These sulphur species are usually very easy to oxidise and their removal from the gas stream by absorption into a dilute aqueous oxidising agent can be effective in de-odorising the air (F.H.H. Valentin, A. North, Odour Control - A Concise Guide, Warren Spring, UK, 1980). However, it is possible to increase the oxidative reaction rate with a catalyst and this enhancement in reaction rate can be such that for most applications (E.H. Stitt, F.J. Taylor, K. Kelly, Catalytically enhanced packed tower scrubbing, in: Proceedings of the Emerging Solutions to VOC \& Air Toxics Control, Clearwater Beach, FA, AWMA, 1996), the catalytic process will be the commercial solution. This paper will discuss research undertaken to investigate the source of the oxidative properties of the catalyst. (C) 1998 Elsevier Science B.V. All rights reserved.
\end{abstract}

Keywords: Odour removal; Catalytic enhancement

\section{Introduction}

The oxidative reaction that occurs on absorption into the aqueous stream of the gas phase hydrogen sulphide is displayed as follows:

$$
\mathrm{H}_{2} \mathrm{~S}+\mathrm{OCl}^{-} \rightarrow \mathrm{S}, \mathrm{S}_{2} \mathrm{O}_{3}^{2-} \mathrm{S}_{2} \mathrm{O}_{4}^{2-}, \mathrm{S}_{4} \mathrm{O}_{6}^{2-}, \mathrm{SO}_{3}^{2-}, \mathrm{SO}_{4}^{2-} \text {. }
$$

The reaction products are numerous and depend upon $\mathrm{pH}$, sodium hypochlorite concentration and the presence or absence of a catalyst. The most usual catalyst is based on nickel; however, industrially, a more complex catalyst that contains both nickel and iron is used [2]. This technology for nuisance odours abatement (the ODORGARD ${ }^{\mathrm{TM}}$

\footnotetext{
*Corresponding author. Tel.: 00441642523749.
}

Process $^{1}$ ) has become well established because the naturally quite fast oxidation of hydrogen sulphide with sodium hypochlorite can be enhanced, specially when the reactants are dilute, by the addition of a catalyst [1]. Thus the process has rather unusual aspects, and to understand the mechanism by which the catalyst brings advantages to the several process techniques have been used to investigate the catalytic reaction. The catalyst has been characterised by resonance photoemission and atomistic simulation. The overall process chemistry has been explored using a laboratory microreactor. With this combination of an understanding the mechanism of the catalytic reaction has been developed.

\footnotetext{
${ }^{1}$ ODORGARD ${ }^{\mathrm{TM}}$ is a trademark of the ICI Group of companies
} 


\section{Experimental}

The catalytic process has been studied using a laboratory based microreactor (see Fig. 8 for a simplified line diagram). Hydrogen sulphide (gas concentration) was determined using Gastec tubes.

The sulphur oxyanions have been measured by a variety of techniques including high performance capillary electrophoresis (thiosulphate, sulphate) and high performance anion exchange chromatography (sulphide). Sulphite was shown not to be present at significant levels in the process. Elemental sulphur was initially measured by turbidity methods; however, it became obvious that the total sulphur balance was sufficiently reliable to allow elemental sulphur to be calculated as the missing material after the determination of all the other important sulphur species.

Model catalysts have been prepared and investigated using resonant photoemission spectroscopy to determine the nature of the density of states at the Fermi level [3]. A co-precipitation route from soluble metal salts $\left(\mathrm{LaCl}_{3}, \mathrm{Sr}\left(\mathrm{NO}_{3}\right)_{2}, \mathrm{NiCl}_{2}\right.$ and $\left.\mathrm{Fe}\left(\mathrm{NO}_{3}\right)_{3}\right)$ in their required molar ratios with sodium carbonate was used. The precipitate was filtered, dried and calcined at $1200^{\circ} \mathrm{C}$. XRD was used to confirm the structure of the prepared catalysts. The resonant photoemission measurements were carried out at the Synchrotron Radiation Source, CLRC Daresbury Laboratory. These measurements used the toroidal grating monochromator (15-90 eV photon energy), the position of the Fermi edge was determined by reference to the Mo sample holder. Atomistic simulation of the effect of dopants was performed using static simulation techniques [4]. Ionic polarisation was treated by a shell model [5] and defect calculations at distancemodelled by the Mott-Littleton approximation [6]. The CASCADE code was used to calculate the energetics of hole and oxygen vacancy formation.

\section{Results and discussion}

The experimental data from the photoemission studies are displayed in Figs. 1-3. The laboratory

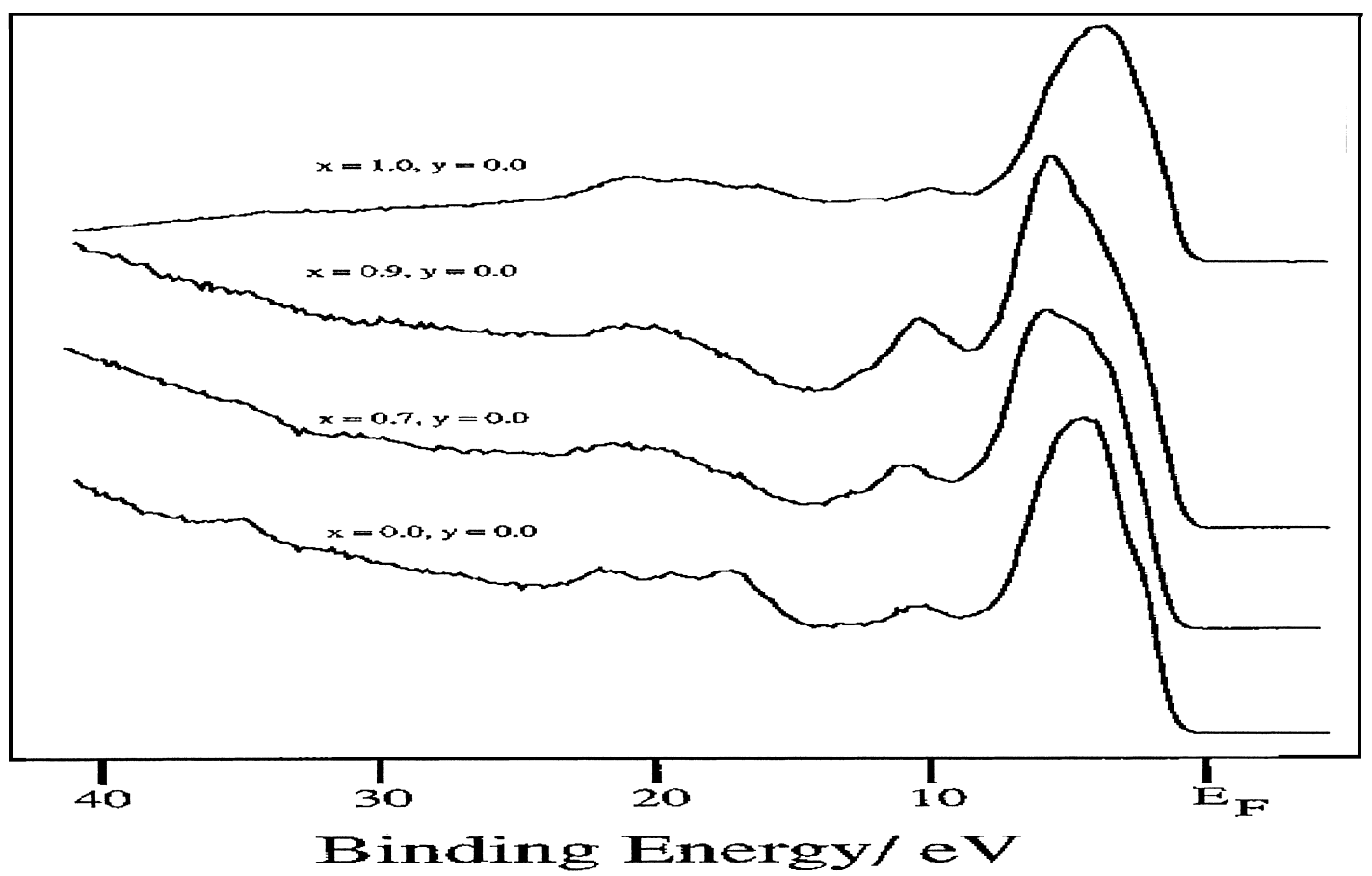

Fig. 1. The photoemission spectra of undoped lanthanum strontium nickelate $x=0 \mathrm{La}_{2} \mathrm{NiO}_{4}, x=0.7 \mathrm{La}_{1.3} \mathrm{Sr}_{0.7} \mathrm{NiO}_{4}, x=0.9 \mathrm{La}_{1.1} \mathrm{Sr}_{0.9} \mathrm{NiO}_{4}, x=1.0$ $\mathrm{La}_{1} \mathrm{Sr}_{1} \mathrm{NiO}_{4}$. 


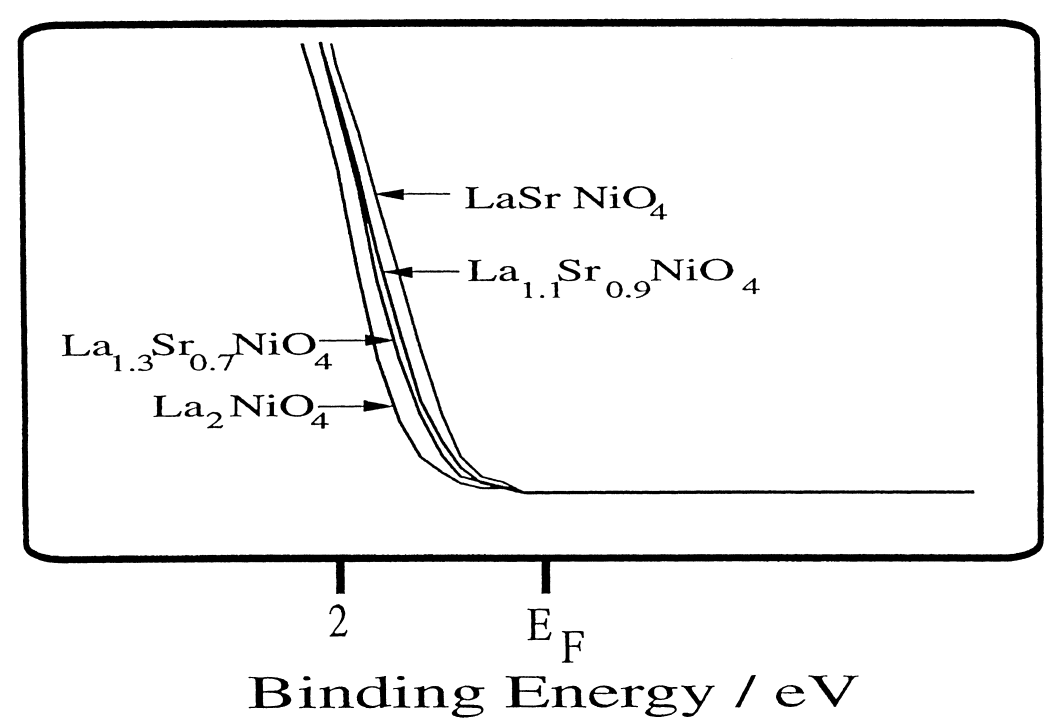

Fig. 2. The photoemission spectra of undoped lanthanum strontium nickelate close to the Fermi level.

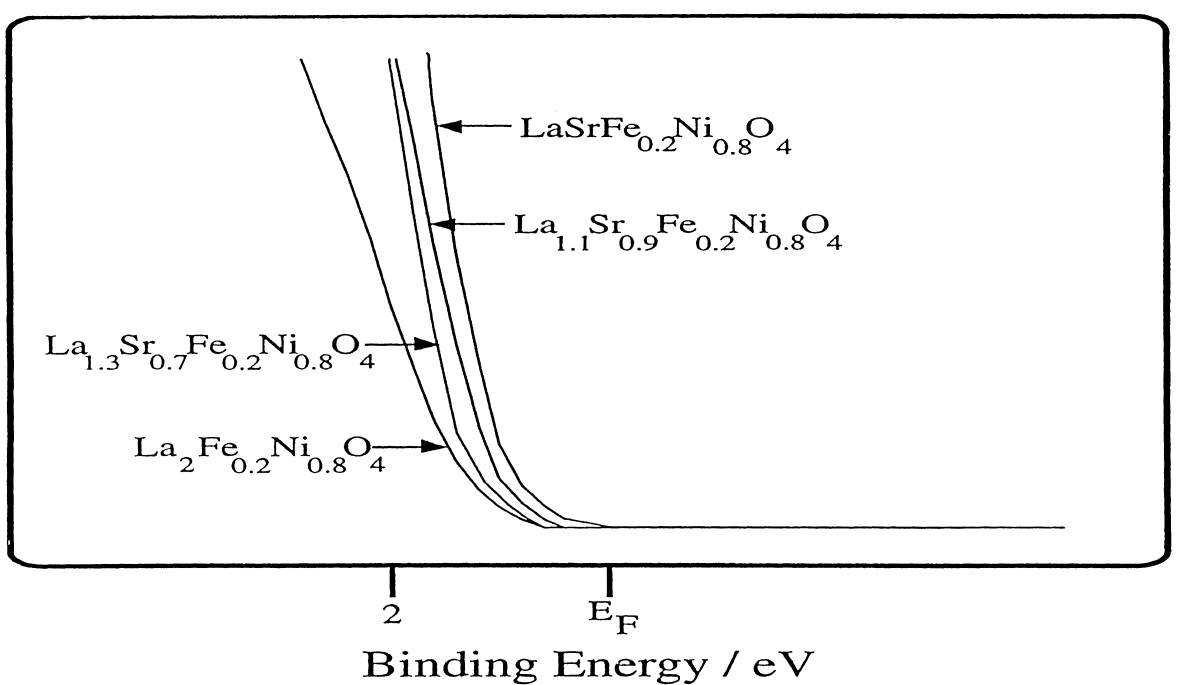

Fig. 3. The photoemission spectra close to the Fermi level of iron doped lanthanum strontium nickelate.

microreactor studies yielded experimental data on the products of hydrogen sulphide oxidation that is displayed in Figs. 6 and 7. Photoemission from a solid is a powerful probe of the filled valence band levels (those below the Fermi energy, $E_{\mathrm{F}}$ ). In recent years, advances in instrumental resolution, combined with the use of synchrotron radiation, have made possible the study of the density of states function very close to the Fermi energy. This is of importance in the study of catalyst materials, as the Fermi energy is essentially equivalent to the chemical potential of the system. The identification of the states closest to the Fermi energy 
thus gives an indication of which cations are most easily oxidised in the system. Careful measurement of the onset of the filled DOS relative to $E_{\mathrm{f}}$ as a function of chemical doping can give an indication of changes in the redox behaviour of a catalyst, which may affect its activity strongly. These measurements are particularly powerful when carried out using a synchrotron source, as in this case, the tuneability of the source allows resonant photoemission to be used to identify the atomic character of these states. Resonant measurements make use of the fact that the cross-section for photoemission from any element is enhanced at certain photon energies unique to that element. Here, for example, we have made use of the resonant enhancement in signal which occurs for the $3 \mathrm{~d}$ transition metals at the $3 \mathrm{p} \rightarrow 3 \mathrm{~d}$ threshold (typically in the range $50-75 \mathrm{eV}$ for the late first row transition metals).

The reasons for the enhancement in activity of the catalyst caused by $\mathrm{Fe}$-doping have been investigated using a complex metal oxide as a model for the catalyst. The system we have chosen is $\mathrm{La}_{2-x} \mathrm{Sr}_{x} \mathrm{Ni}_{1-y} \mathrm{Fe}_{y} \mathrm{O}_{4+\mathrm{d}}$, where we may control the $\mathrm{Ni}$ :Fe ratio by varying $y$, but can also control the $\mathrm{Ni}$ and $\mathrm{Fe}$ valences by varying $x$. The effect of doping $\mathrm{Sr}$ for $\mathrm{La}$ is to increase the oxidation states of $\mathrm{Ni}$ and $\mathrm{Fe}$, so that it is possible to generate unusually high $\mathrm{Ni}(\mathrm{III})$ and $\mathrm{Fe}(\mathrm{IV})$ valences [7]. Resonant photoemission for this system shows that the part of the valence band closest to the Fermi energy has both $\mathrm{Ni}$ and $\mathrm{Fe}$ character, consistent with the ease with which these cations may be oxidised in the catalyst $[3,8]$. When the $x=y=0$ material is doped with $\mathrm{Sr}$ (increasing the $\mathrm{Ni}$ valency), we see a movement of the valence band edge towards the Fermi level (Figs. 1 and 2, $x$ increasing from 0 to 0.9 ). However, this shift is significantly larger for samples containing a few per cent Fe than for iron-free samples $(y=0)$ (Fig. 3). Thus the effect of adding small amounts of $\mathrm{Fe}$ appears to be modify strongly the electronic structure of the material close to the Fermi energy, such that the catalyst is more easily oxidised when $\mathrm{Fe}$ is added. We have also used photoemission to study the chemisorption of small probe molecules including water. We find that the surface reactivity is enhanced by $\mathrm{Sr}$ doping, as the average oxidation state of the transition metal ions is raised [8].

Our studies show that the overall reactivity of the catalyst is enhanced as the transition metal oxidation state increases, but the addition of $\mathrm{Fe}$ has a particularly strong effect in modifying the chemical potential of the system to assist the catalytic redox process. Photoemission analysis shows the significant effect on the Ni 3d DOS at relatively small levels of iron doping that suggests a close proximity to $\mathrm{Fe}$ [8]. Thus the data can be interpreted in terms of a Ni-O-Fe bridge as being the critical structure for the catalysis and indicate that $\mathrm{Ni}(\mathrm{III})$ is more easily produced by the presence of $\mathrm{Fe}-$ doping. This would explain the influence of $\mathrm{Fe}$ on the

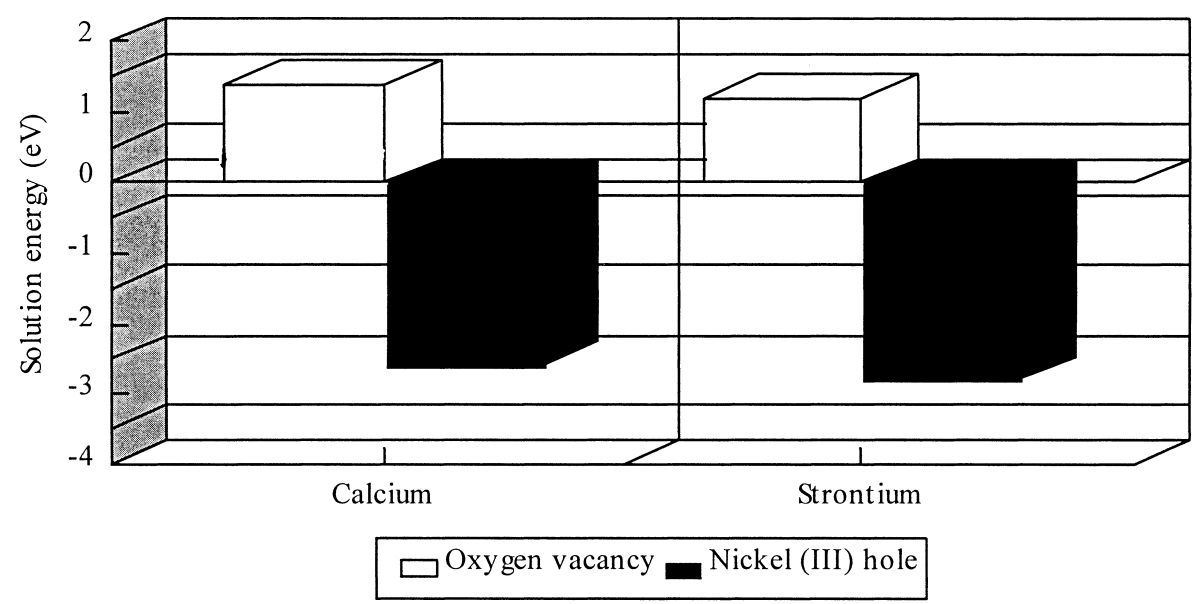

Fig. 4. Solution energies for oxygen vacancy and hole formation with calcium and strontium doping. 
activity of the catalyst, as the catalytic process is thought to involve a rate-limiting $\mathrm{Ni}(\mathrm{II})-\mathrm{Ni}$ (III) interconversion [9].

Atomistic simulation techniques have been used to calculate the stability of various dopant induced defects within the structure as a function of Fe-doping [10]. The simulation was based on the Born model of ionic solids and this technique has been successfully applied to other oxide catalysts [11]. The lanthanum nickelate $\left(\mathrm{La}_{2} \mathrm{NiO}_{4}\right)$ was used as the starting point and its structure was calculated and compared with the known unit cell dimensions to confirm the interatomic potentials used. From this perfect crystal defect sites were introduced and the energy of the new structure was calculated. Thus the facility with which these sites may be produced was determined.

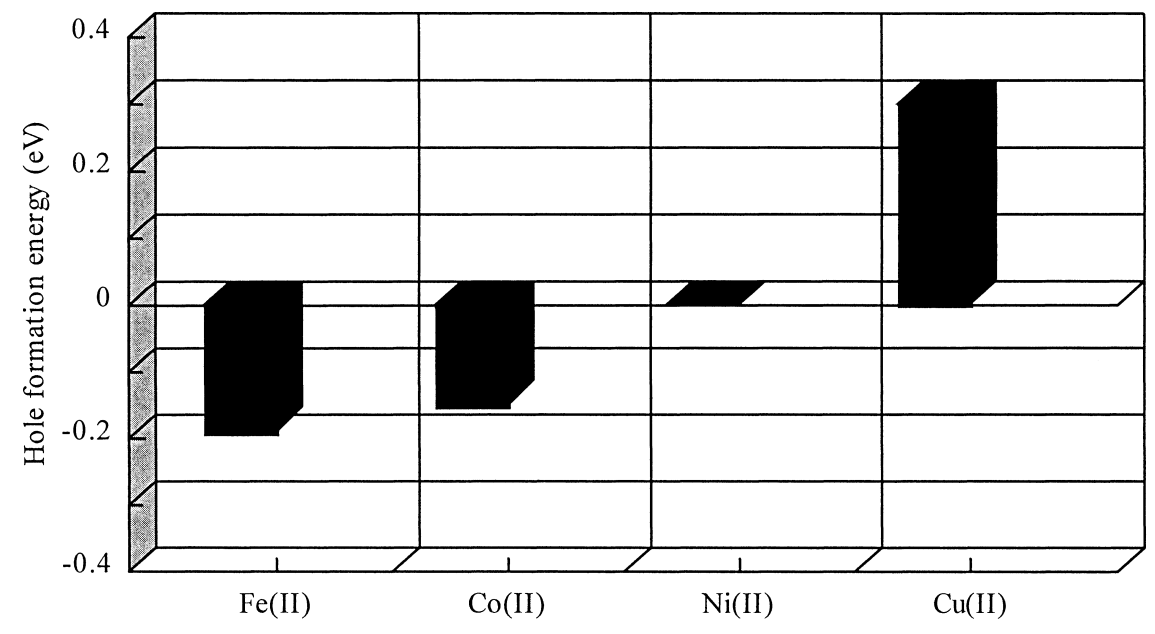

Fig. 5. Hole formation energy for various dopants.

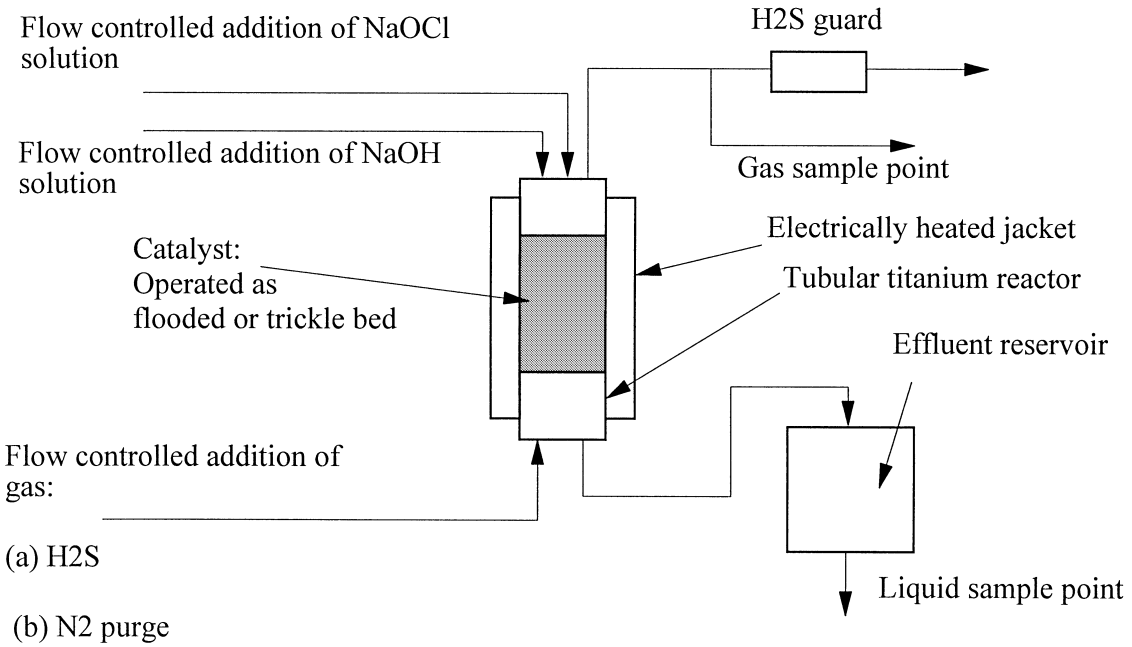

Fig. 6. Simplified line diagram of the microreactor for hydrogen sulphide oxidation. 
The simulation study predicted that hole formation occurs preferentially on the $\mathrm{Ni}$ via $\mathrm{Ni}(\mathrm{III})$ rather than charge compensation by an oxygen vacancy as a result of $\mathrm{Ca}$ or $\mathrm{Sr}$ doping Fig. 4. The investigation also showed that iron was the dopant that would most enhance the nickel hole formation process Fig. 5. By placing the iron in the unit cell such that $\mathrm{Ni}-\mathrm{O}-\mathrm{Fe}$ were formed in distinction to $\mathrm{Ni}-\mathrm{O}$...O-Fe (i.e., long range interactions) it was also demonstrated that the $\mathrm{Ni}-\mathrm{O}-\mathrm{Fe}$ structures were required to enhance hole formation. Finally the postulated $\mathrm{Ni}(\mathrm{IV})$ was shown to be energetically possible (approximately $0.2 \mathrm{eV}$ greater energy than the $\mathrm{Ni}(\mathrm{III})$ hole) as required by the reaction mechanism Fig. 9. [10].

The catalytic and non-catalytic reactions have been studied in a three phase reactor Fig. 6. The reactor was charged with either the commercial catalyst $(100 \mathrm{ml})$ or alumina spheres (for the blank reaction). The hydrogen sulphide gas (1000 ppm v/v) was fed to the bottom of the reactor, the sodium hypochlorite

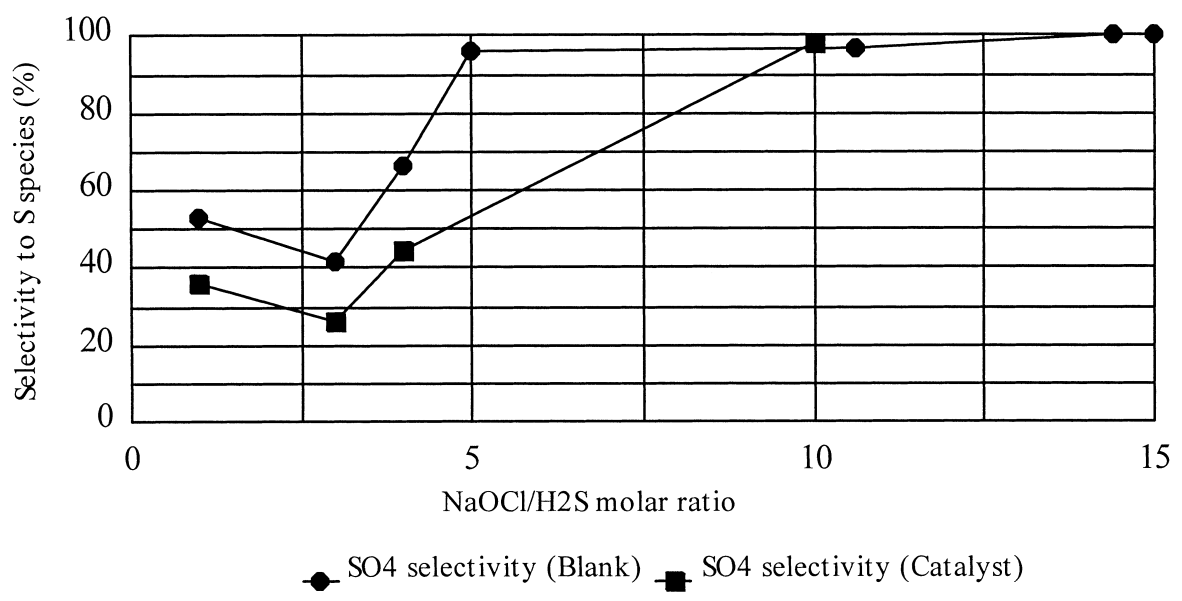

Fig. 7. Sulphate selectivity for the sodium hypochlorite oxidation of hydrogen sulphide.
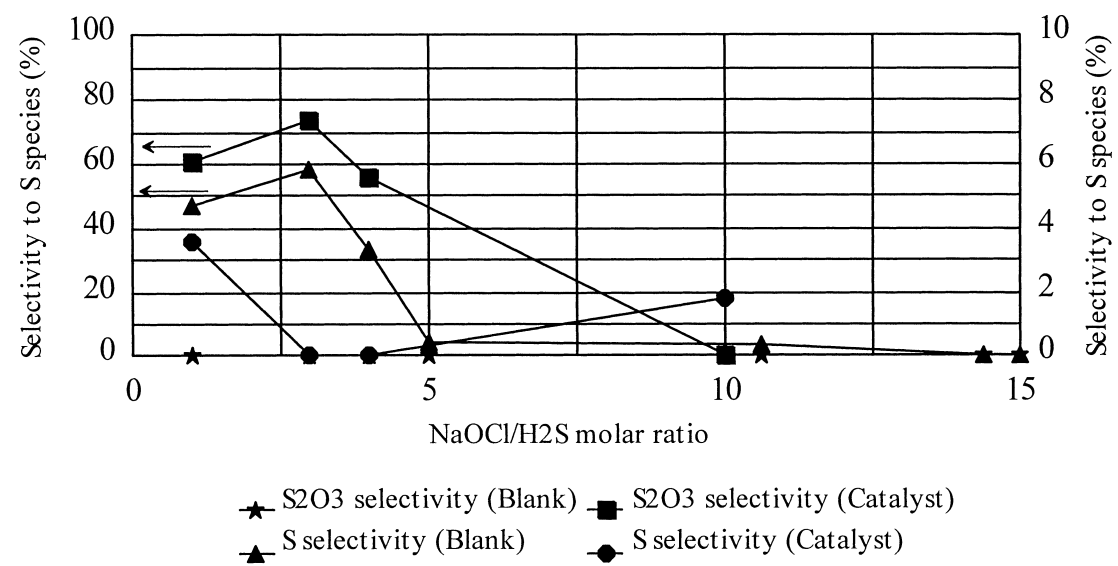

Fig. 8. Sulphur and thiosulphate selectivity for the sodium hypochlorite oxidation of hydrogen sulphide - first $y$ axis: $\mathrm{S}_{2} \mathrm{O}_{3}$ (catalyst), $\mathrm{S}$ (blank) see arrows; second $y$ axis: $\mathrm{S}$ (catalyst), $\mathrm{S}_{2} \mathrm{O}_{3}$ (blank). 


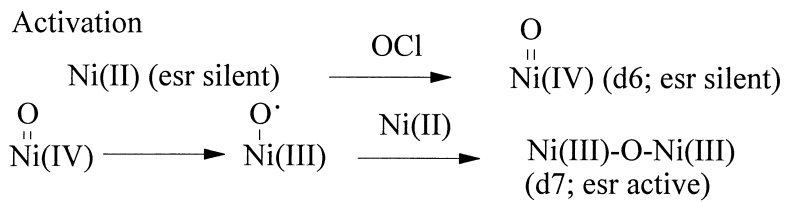

$\mathrm{Ni}(\mathrm{III}), \mathrm{Ni}(\mathrm{II})$ electron transfer reaction promoted by $\mathrm{Fe}$ Interception by $\mathrm{SH}$ and formation of the $\mathrm{S}-\mathrm{O}$ bond

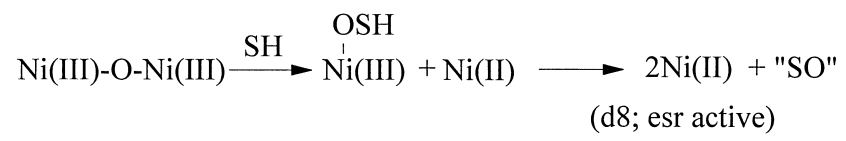

Fig. 9. Proposed catalytic mechanism.

and sodium hydroxide solutions were fed countercurrent to the gas. Sodium hydroxide was added to ensure an alkaline environment ( $\mathrm{pH}>9.5)$. The exit gas was analysed for residual $\mathrm{H}_{2} \mathrm{~S}$ and the liquid effluent was analysed for sulphur oxidation products.

Three major oxidation products were observed, elemental sulphur, thiosulphate and sulphate. At very low hypochlorite to $\mathrm{H}_{2} \mathrm{~S}$ ratios hydrosulphide $\left(\mathrm{HS}^{-}\right.$) was also detected. The distribution of the three major products for the catalytic and non-catalytic reactions are displayed in. The selectivity to sulphate for the catalytic and non-catalytic reactions (Fig. 7) shows complete oxidation to sulphate at high $\mathrm{NaOCl} / \mathrm{H}_{2} \mathrm{~S}$ ratios and this selectivity decreases as the ratio approaches the stoichiometric value (4). There is, however, a difference in the chemistry underlying this change that can be seen in Fig. 8.

The non-catalytic reaction starts to make elemental sulphur as the $\mathrm{NaOCl} / \mathrm{H}_{2} \mathrm{~S}$ ratio decreases. The catalytic reaction continues to make sulphur oxyanions (thiosulphate). Thus the catalyst is enhancing the formation of soluble products from $\mathrm{H}_{2} \mathrm{~S}$ via the formation of S-O bonds. This ability can be visualised in terms of a surface sulphur species that can be intercepted by a reactive $\mathrm{O}_{a d}$ derived from sodium hypochlorite (Fig. 9). The structure of the site producing this surface $\mathrm{O}_{\mathrm{ad}}$ has been discussed elsewhere [9].

\section{Conclusions}

The redox activity of the nickel was enhanced in the presence of $\mathrm{Fe}$ and this was predicted by the atomistic simulations and observed in the resonant photoemission. The resultant catalyst had an excellent activity for the oxidation of sulphur species through to oxyanions and suppressed the elemental sulphur byproduct.

\section{Acknowledgements}

The photoemission and the atomistic simulation were undertaken by Mr. J.F. Howlett and Ms. J. Hollingworth, Department of Physics, UMIST, Manchester, UK, and Mr. M.S.D. Read, Department of Chemistry, University of Surrey, Guildford, Surrey, UK, as part of their postgraduate studies. Mr. W.F.R. Groenen, University of Twente, Netherlands, carried out the reactor studies at ICI Katalco.

\section{References}

[1] F.H.H. Valentin, A. North, Odour Control - A Concise Guide, Warren Spring, UK, 1980.

[2] E.H. Stitt, F.J. Taylor, K. Kelly, Catalytically enhanced packed tower scrubbing, in: Proceedings of the Emerging Solutions to VOC \& Air Toxics Control, Clearwater Beach, FA, AWMA, 1996.

[3] W.R. Flavell, J. Hollingworth, J.F. Howlett, A.G. Thomas, M. Sarker, S. Squire, Z. Hashim, M. Mian, P.L. Wincott, D. Teehan, S. Downes, F.E. Hancock, J. Synchrotron Rad. 2 (1995) 264.

[4] C.R.A. Catlow, W.C. Mackrodt, Computer simulation of solids, Lecture Notes in Physics, vol. 166, Springer, Berlin, 1982.

[5] B.G. Dick, A.W. Overhauser, Phys. Rev. 112 (1958) 90. 
[6] N.F. Mott, M.J. Littleton, Trans. Farad. Soc. 34 (1938) 485.

[7] R. Benloucif, N. Nguyen, J.M. Greneche, B. Raveau, J. Phys. Chem. Solids 52 (1991) 381.

[8] J.F. Howlett, W.R. Flavell, A.G. Thomas, J. Hollingworth, S. Warren, Z. Hashim, M. Main, S. Squire, H.R. Aghabozorg, M. Sarker, P.L. Wincott, D. Teehan, S. Downes, D.S.-L. Law and F.E. Hancock, J. Chem. Soc., Faraday Discuss. (1997) 105.

[9] F. King, F.E. Hancock, Catalysis Today 27 (1996) 203.

[10] M.S. Islam, M.S.D. Read, F.E. Hancock, in preparation.

[11] M.S. Islam, D.J. Ilett, S.C. Parker, J. Phys. Chem. 98 (1994) 9637. 